\title{
Preparation of Flame Retardant Modified with Titanate for Asphalt Binder
}

\author{
Bo Li, ${ }^{1,2}$ Jianxun Liu, ${ }^{3}$ Feng Han, ${ }^{1}$ Xiaoling Li, ${ }^{1}$ Liangying Li, ${ }^{1}$ \\ Yanbo Li, ${ }^{1,2}$ and Xiaofeng Duan ${ }^{1}$ \\ ${ }^{1}$ School of Civil Engineering, Lanzhou Jiaotong University, Lanzhou, Gansu 730070, China \\ ${ }^{2}$ Gansu Lufu Engineering \& Technology Co., Ltd, Lanzhou, Gansu 730070, China \\ ${ }^{3}$ Gansu Road and Bridge Construction Group Co. Ltd, Lanzhou, Gansu 730030, China \\ Correspondence should be addressed to Bo Li; libolzjtu@gmail.com
}

Received 18 June 2014; Revised 11 August 2014; Accepted 21 August 2014; Published 15 October 2014

Academic Editor: Luigi Nicolais

Copyright (C) 2014 Bo Li et al. This is an open access article distributed under the Creative Commons Attribution License, which permits unrestricted use, distribution, and reproduction in any medium, provided the original work is properly cited.

\begin{abstract}
Improving the compatibility between flame retardant and asphalt is a difficult task due to the complex nature of the materials. This study explores a low dosage compound flame retardant and seeks to improve the compatibility between flame retardants and asphalt. An orthogonal experiment was designed taking magnesium hydroxide, ammonium polyphosphate, and melamine as factors. The oil absorption and activation index were tested to determine the effect of titanate on the flame retardant additive. The pavement performance test was conducted to evaluate the effect of the flame retardant additive. Oxygen index test was conducted to confirm the effect of flame retardant on flame ability of asphalt binder. The results of this study showed that the new composite flame retardant is more effective in improving the compatibility between flame retardant and asphalt and reducing the limiting oxygen index of asphalt binder tested in this study.
\end{abstract}

\section{Introduction}

Asphalt is a complex mixture of organic molecules that vary in chemical compositions and molecular weights [1-3]. Owing to the asphalt binder chemical constitution, however, the material is quite flammable and produces smoke and poisonous gases while burning [4]. Due to these properties, it is dangerous to use asphalt binder in road tunnel pavements, gas stations, and so forth [5-7]. An expanded growth of asphalt application concurrent with the proliferation of safety standards being set by government and private agencies has indicated that it is of primary importance to reduce the flammability of asphalt materials [8].

Generally, five burning processes are considered to be involved in asphalt flammability: heating, decomposition, ignition, combustion, and propagation. Flame retardation can be accomplished by the disruption of the burning process at one or more stages so that the process is terminated within an acceptable period of time, preferably before ignition actually occurs [8]. Asphalt binders with excellent flame retardation capability have been prepared successfully by adding various flame retardants such as antimony trioxide, decabromodiphenyl ether, aluminum trihydroxide, and zinc borate. Different flame retardants exhibit different mechanisms of flame resistance [9-11]. So far, halogen-based flame retardants have been extensively employed for this purpose, but the halogen-containing materials easily released a good deal of poisonous smoke and corrosive fumes in their burning process [12-14]. As consciousness increases in environmental protection and technology advances in flame retardants, the development trend of flame retardants will be halogen-free, nontoxic, and smoke suppressing $[15,16]$. Most halogen-free formulations are based on inorganic fillers such as metallic hydroxide and expandable graphite [17]. In recent years, magnesium hydroxide has become one of the most popular replacements for halogen-based flame retardants and has been widely used in polymer materials [18]. However, the disadvantages of inorganic fire-retardant agents such as low fire-retardant efficiency, large adding amount, strong polarity, and poor compatibility with asphalt limit its applications 
$[19,20]$. Furthermore, it still has a potential threat for pavement performance at larger concentration of around $20 \%$ by weight. Therefore, it is necessary to develop a low dosage of flame retardant, to create equilibrium between flame retardant properties and pavement performance.

Since magnesium hydroxide, ammonium polyphosphate, and other materials are inorganic fillers, which have inert and hydrophilic nature, they are of poor compatibility with asphalt. Coarse particles lack the reinforcement. Finer particles often have poor dispersion, which can cause particles to become aggregates. Therefore, it is necessary to use surface treatment of inorganic fillers in order to overcome the defect itself and receive the new physical and chemical properties in the surface of the particle. In recent years, titanate coupling agent is used to modify the inorganic fillers [21, 22] because the titanate coupling agent has a unique structure which has a good coupling effect for the polymer and filler. Therefore, it can improve the dispensability of the flame retardant in asphalt and improve flame retardancy.

The objective of this study is to develop a low dosage compound flame retardant and improve the compatibility between flame retardants and asphalt. An orthogonal experiment was designed taking magnesium hydroxide, ammonium polyphosphate, and melamine as factors. The oil absorption and activation indexes were tested to determine the effect of titanate on the flame retardant additive. The pavement performance test was conducted to evaluate the effect of the flame retardant additive. Oxygen index test was conducted to confirm the effect of flame retardant on flame ability of asphalt binder.

\section{Materials and Test Program}

2.1. Materials. An asphalt binder was used in this study. It was from Kelamayi crude source. Table 1 summarizes the properties of the binder in this study.

Three main ingredients of the flame retardants used in this paper include magnesium hydroxide, melamine, and ammonium polyphosphate. Magnesium hydroxide is a new type of flame retardant filler. It can reduce the surface temperature of the asphalt while burning because it releases water and can absorb large quantities of latent heat when it is heated, which is helpful in inhibiting the decomposition of the polymer and cooling the generated combustible gas. Ammonium polyphosphate (APP) has the role of the acid source, which can form an intumescent flame retardant system and have a better synergistic flame retardant effect with $\mathrm{Mg}(\mathrm{OH})_{2}$. Melamine itself has flame retardance whose decomposition temperature is over $300^{\circ} \mathrm{C}$, which can be dissolved in the asphalt. As described above, magnesium hydroxide, ammonium polyphosphate, and melamine can be treated by surface polarity activation using a titanate coupling agent, which can improve flame retardant's lipophilicity and dispersibility. And their physical properties are shown in Tables 2 and 3.

2.2. Preparation of Flame Retardant. Magnesium hydroxide, ammonium polyphosphate, and melamine were mixed together and dried in the oven to reduce their surface water after they were weighed accurately using an electronic balance. We can name the composite flame retardant as FRA. The titanate coupling agent was added in the composite flame retardant. Then they were mixed well with a stirrer and dried in the oven. A new flame retardant was obtained. We can name it as FRA-Ti. Their quality and proportion were determined by orthogonal table, respectively. Table 4 shows the factors and levels in orthogonal test. Table 5 shows the factors combination in an orthogonal test.

\subsection{Preparation of Asphalt Binder Modified with Flame} Retardant. The asphalt was modified by adding the different FRA-Ti into asphalt binder and mixing with the stirrer. The specific preparation process and steps are as follows. $1000 \mathrm{~g}$ asphalt was heated at about $140^{\circ} \mathrm{C}$ after it was dehydrated at $105^{\circ} \mathrm{C}$. And $50 \mathrm{~g}$ FRA-Ti was added into the asphalt binder and stirred about $30 \mathrm{~min}$ at $500 \mathrm{r} / \mathrm{min}$.

2.4. Pavement Performance. The pavement performance test was conducted to evaluate the effect of the flame retardant additive including the softening point, penetration, ductility, and elastic recovery in accordance with the test requirements of Technical Specification for Construction of Highway Asphalt Pavements (JTG F40-2004).

2.5. Activation Index. Modified activation index of flame retardancy was measured by the following method: a cylinder volume of $20 \mathrm{~mL}$ water was added to a separatory funnel, along with $5 \mathrm{~g}$ of the modified flame retardant, 1 min shaking up and down 120 times, and allowed to stand over $1 \mathrm{~h}$, and then opening the stopcock deposition on the bottom of the sample discharge, drying, weighing, with the original mass weighed $(5 \mathrm{~g})$ minus the mass of the sample deposition indicates the floating portion of the original mass. Activation index (AI) is calculated as follows:

$$
\mathrm{AI}=\frac{\left(m_{0}-m_{1}\right)}{m_{0}} \times 100 \%,
$$

where $m_{0}$ is original mass weighed ( $\left.5 \mathrm{~g}\right)$ and $m_{1}$ is the mass after activation.

2.6. Oil Absorption. Oil absorption rate was measured by titrating fat dioctyl phthalate (DOP) in the flame retardant samples. In the process of titration, the flame retardant should be constantly turning. It reaches the titration end point when flame retardant resembles "dough." And also note the before and after titration DOP quality. The oil absorption rate (OAR) is defined in

$$
\mathrm{OAR}=\frac{M_{\mathrm{DOP}}}{M_{\mathrm{FRA}}} \times 100 \%,
$$

where $M_{\mathrm{DOP}}$ is used mass of DOP and $M_{\mathrm{FRA}}$ is the original mass of flame retardant.

2.7. Limiting Oxygen Index. Flame retardancy of modified asphalt binder was evaluated by the limiting oxygen index 
TABLE 1: Properties of virgin binders.

\begin{tabular}{lccccc}
\hline Test items & $\begin{array}{c}\text { Penetration } \\
\left(100 \mathrm{~g}, 5 \mathrm{~s}, 25^{\circ} \mathrm{C}\right) / 0.1 \mathrm{~mm}\end{array}$ & $\begin{array}{c}\text { Ductility } \\
\left(5^{\circ} \mathrm{C}\right) / \mathrm{cm}\end{array}$ & $\begin{array}{c}\text { Softening } \\
\text { point } /{ }^{\circ} \mathrm{C}\end{array}$ & Mass loss & $\begin{array}{c}\text { Residue after RTFOT } \\
\text { Penetration ratio } \\
\text { of } 25^{\circ} \mathrm{C} / \%\end{array}$ \\
\hline KLMY-90 & 98 & 29.7 & 48 & -0.188 & 80 \\
\hline
\end{tabular}

TABLE 2: Physical properties of $\mathrm{Mg}(\mathrm{OH})_{2}$, APP, and MEL.

\begin{tabular}{lccc}
\hline & $\mathrm{Mg}(\mathrm{OH})_{2}$ & APP & Melamine \\
\hline Outward appearance & White powder & White powder and good dispersion & White single crystals \\
Density & $2.388 \mathrm{~g} / \mathrm{cm}^{3}$ & $1.732 \mathrm{mg} / \mathrm{cm}^{3}$ & $1.572 \mathrm{mg} / \mathrm{cm}^{3}$ \\
Initial decomposition temperature & $>300^{\circ} \mathrm{C}$ & $>250^{\circ} \mathrm{C}$ & $>300^{\circ} \mathrm{C}$ \\
\hline
\end{tabular}

TABLE 3: Physical properties of titanate coupling agent.

\begin{tabular}{lcccccc}
\hline Test items & $\begin{array}{c}\text { Outward } \\
\text { appearance }\end{array}$ & Molecular & Molecular weight & Content & Density & $\begin{array}{c}\text { Benzene } \\
\text { dissolution test }\end{array}$ \\
\hline Titanate & $\begin{array}{c}\text { Buff oily } \\
\text { liquid }\end{array}$ & $\mathrm{C}_{16} \mathrm{H}_{36} \mathrm{O}_{4} \mathrm{Ti}$ & 340.36 & $\geq 98 \%$ & $0.999-1.003$ & Qualified \\
\hline
\end{tabular}

TABLE 4: The factors and level in orthogonal test.

\begin{tabular}{|c|c|c|c|c|}
\hline Level & (A) $\mathrm{Mg}(\mathrm{OH})_{2}(\mathrm{~g})$ & (B) APP (g) & (C) Melamine (g) & (D) Titanate (\%) \\
\hline 1 & 25 & 33 & 15 & 5 \\
\hline 2 & 20 & 35 & 17.5 & 5.5 \\
\hline 3 & 15 & 38 & 20 & 6 \\
\hline
\end{tabular}

TABLE 5: The design of orthogonal test.

\begin{tabular}{cccccc}
\hline & $\mathrm{A}$ & $\mathrm{B}$ & $\mathrm{C}$ & $\mathrm{D}$ & Orthogonal combination \\
\hline 1 & 1 & 1 & 1 & 1 & $\mathrm{~A}_{1} \mathrm{~B}_{1} \mathrm{C}_{1} \mathrm{D}_{1}$ \\
2 & 1 & 2 & 2 & 2 & $\mathrm{~A}_{1} \mathrm{~B}_{2} \mathrm{C}_{2} \mathrm{D}_{2}$ \\
3 & 1 & 3 & 3 & 3 & $\mathrm{~A}_{1} \mathrm{~B}_{3} \mathrm{C}_{3} \mathrm{D}_{3}$ \\
4 & 2 & 1 & 2 & 3 & $\mathrm{~A}_{2} \mathrm{~B}_{1} \mathrm{C}_{2} \mathrm{D}_{3}$ \\
5 & 2 & 2 & 3 & 1 & $\mathrm{~A}_{2} \mathrm{~B}_{2} \mathrm{C}_{3} \mathrm{D}_{1}$ \\
6 & 2 & 3 & 1 & 2 & $\mathrm{~A}_{2} \mathrm{~B}_{3} \mathrm{C}_{1} \mathrm{D}_{2}$ \\
7 & 3 & 1 & 3 & 2 & $\mathrm{~A}_{3} \mathrm{~B}_{1} \mathrm{C}_{3} \mathrm{D}_{2}$ \\
8 & 3 & 2 & 1 & 3 & $\mathrm{~A}_{3} \mathrm{~B}_{2} \mathrm{C}_{1} \mathrm{D}_{3}$ \\
9 & 3 & 3 & 2 & 1 & $\mathrm{~A}_{3} \mathrm{~B}_{3} \mathrm{C}_{2} \mathrm{D}_{1}$ \\
\hline
\end{tabular}

(LOI, HC-2, Jiangning Instruments Co., Ltd., China). Limiting oxygen index methods are widely used to measure the flammability of polymers and to investigate the effectiveness of flame retardants. Flame retardancy was assessed by the LOI according to ASTM D-2863. For testing, the top of the sample was ignited by a gas flame, which was stopped once ignition has occurred. Then, the lowest oxygen concentration in a flowing mixture of nitrogen and oxygen, which just supports sustained burning, can be determined. The effectiveness of flame retardants is measured by the changes in the critical oxygen concentration. The LOI is defined in

$$
\mathrm{LOI}=\frac{\Phi_{\mathrm{cr}}\left(\mathrm{O}_{2}\right)}{\Phi_{\mathrm{cr}}\left(\mathrm{O}_{2}\right)+\Phi\left(\mathrm{N}_{2}\right)},
$$

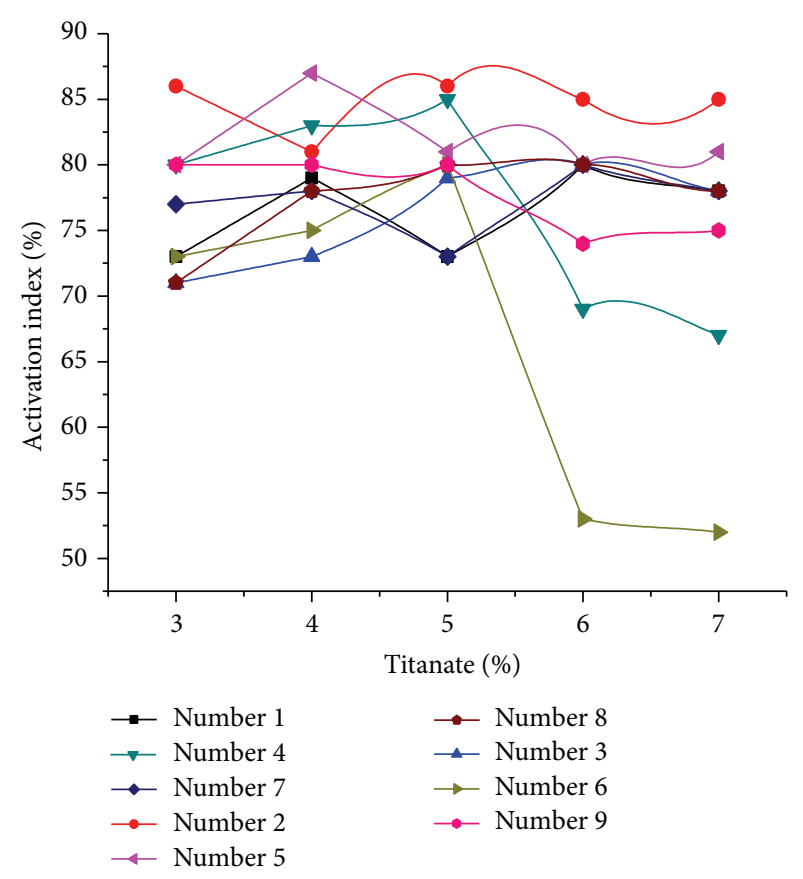

FIGURE 1: Oil absorption of FRA modified by titanate.

where $\Phi_{\mathrm{cr}}\left(\mathrm{O}_{2}\right)$ and $\Phi\left(\mathrm{N}_{2}\right)$ are the minimum oxygen concentration and the relevant nitrogen concentration in the inflow gases, respectively. 


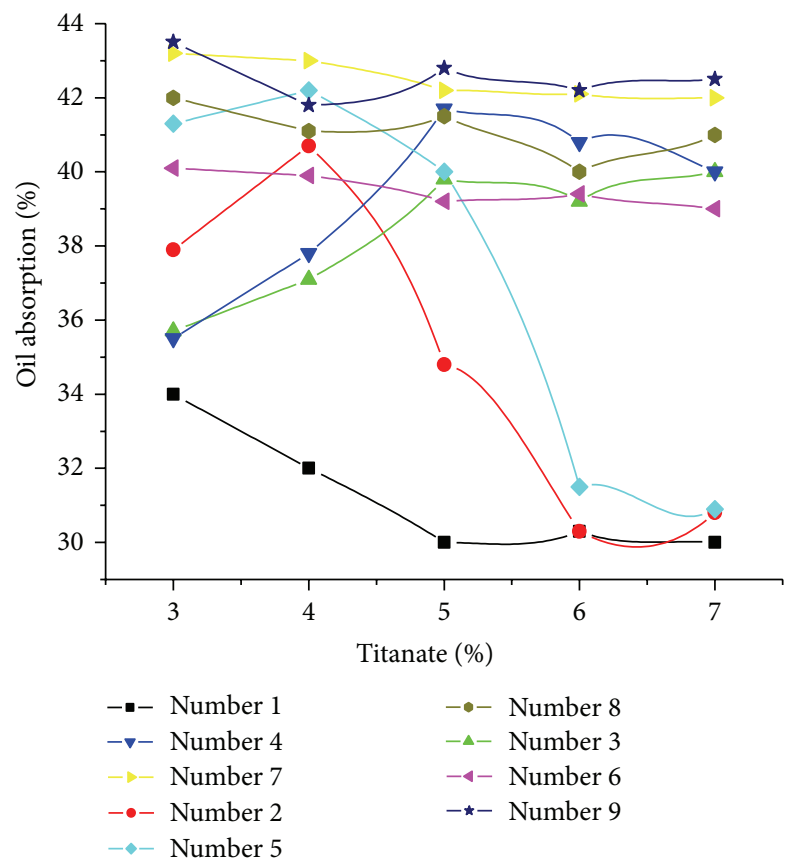

FIGURE 2: Activation index of FRA modified by titanate.

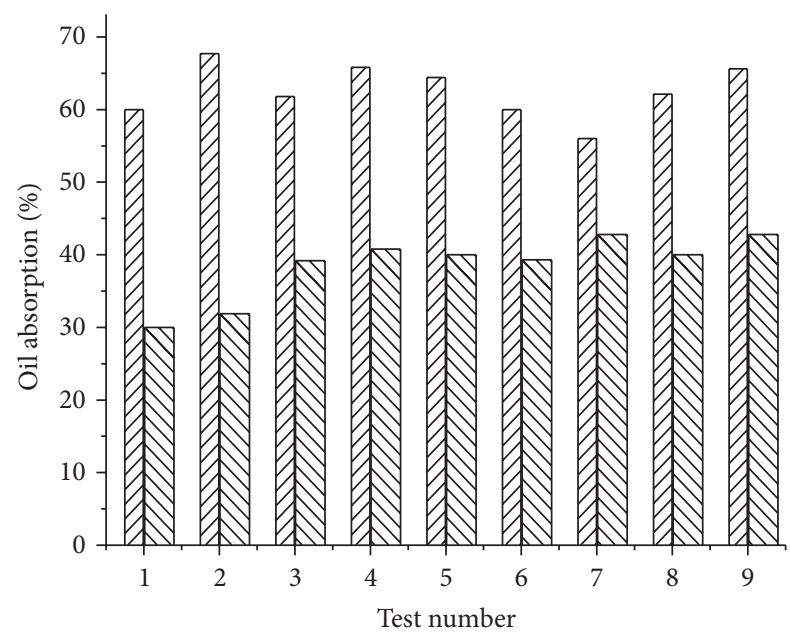

ZIA FRA

MIV FRA-Ti

FIgURE 3: Oil absorption of FRA and FRA-Ti.

\section{Results and Discussions}

3.1. Effect of Titanate on the Oil Absorption and Activation Index. After the titanate coupling agent was added, the oil absorption and activation index of nine FRA were measured and results are illustrated in Figures 1 and 2, respectively. A general trend found that oil absorption of FRA with titanate was stable $40-44 \%$ except number 1 , number 2 , and number 5. After titanate amount increasing to $6 \%$, the oil absorption rate reached a stable value. The general trend of activation index is similar to the findings for oil absorption as shown in Figure 1. After the titanate amount was increased

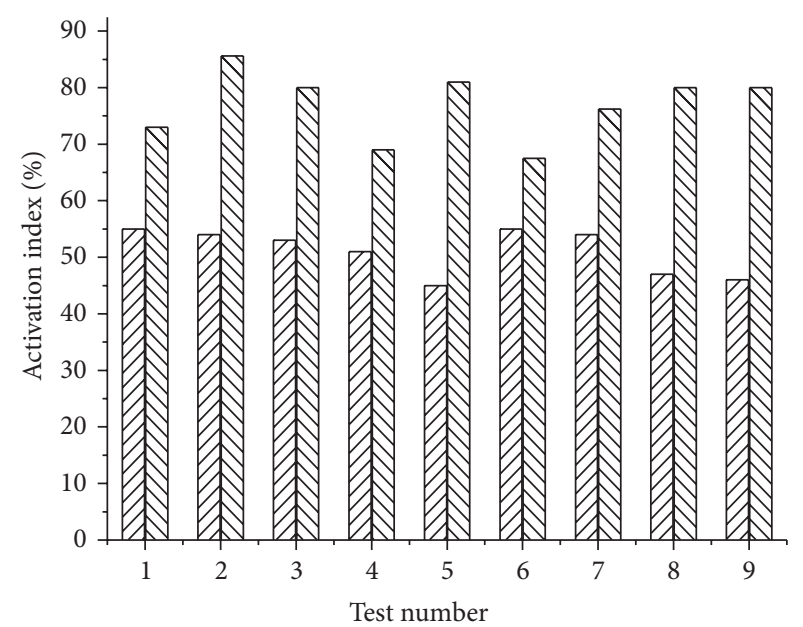

ZIIA FRA

MIV FRA-Ti

FIgURE 4: Activation index of FRA and FRA-Ti.

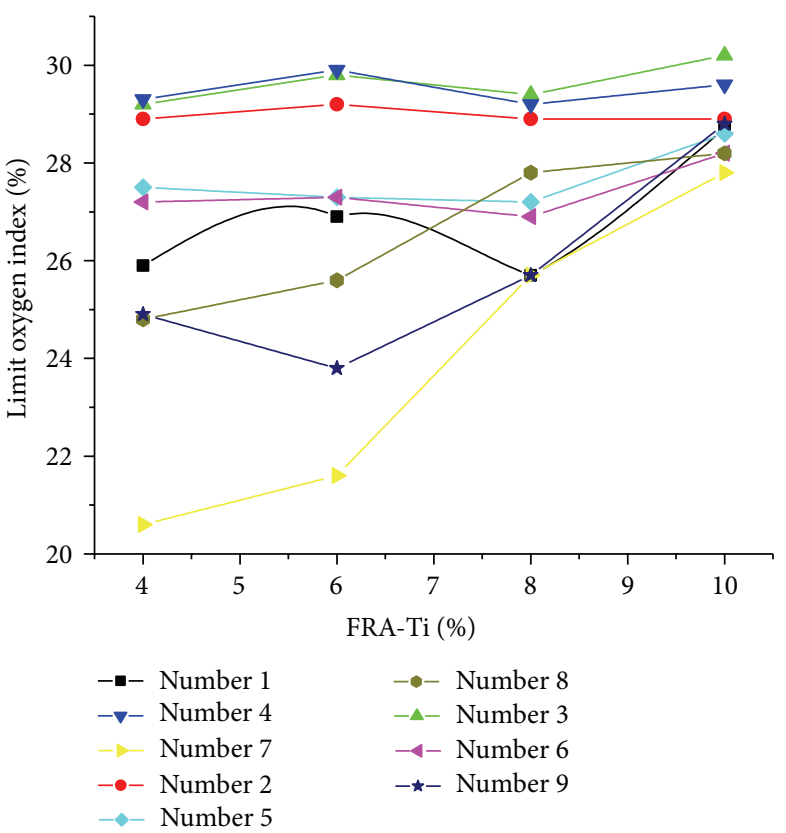

FIGURE 5: Limiting oxygen index (LOI) of asphalt with FRA-Ti.

to $5 \%$, their activation index reached a stable value except number 4 , number 5 , and number 6 . The main reason is thought to be that FRA particle surface is gradually covered by coupling molecules with the increase of the amount of titanate, which lead the surface polarity to a gradual transition from hydrophilic to lipophilic, decreased oil absorption, and instable activation index. When titanate was added to the optimal dosage, the surfaces of each FRA particle were covered by a titanate coupling agent. After more than the optimum amount, the excess coupling is only dispersed in the organic phases, which have little effect on surface modification for FRA [23]. It indicated that the optimal 
dosage of titanate is $6 \%$ considering the oil absorption and activation index of nine FRA.

The results of oil absorption and activation index of nine FRA with and without titanate coupling agent are showed in Figures 3 and 4, respectively. The general trend found that oil absorption rate decreased and activation index increased for FRA modified by titanate.

\subsection{Effect of Flame Retardant on the Limiting Oxygen Index.} Limiting oxygen index estimates the flame residence. It is defined as the lowest $\mathrm{O}_{2}$ concentration to maintain burning in mixed gas with $\mathrm{N}_{2}$ and $\mathrm{O}_{2}$. The $\mathrm{O}_{2}$ concentration in air is $21 \%$. When LOI $\leq 21 \%$, this material is easily burned; when LOI is between $21 \%$ and $27 \%$, this material can burn; and when LOI $\geq 27 \%$, this material should be autoextinguished. The LOI of flame-retarded asphalt which was above $23 \%$ was put forward by Hui-qiang and Shi-zhou [24]. Figure 5 shows the LOI result of nine FRA at different proportion. The general trend found that the LOI of asphalt with FRA$\mathrm{Ti}$ is 3\% larger than that of virgin asphalt (21.3\%). Though LOI of No7 is not changed obviously at the $4 \%$ and $6 \%$ FRA-Ti, it increased and reached the same level when $8 \%$ FRA-Ti was added into asphalt. We can conclude that the minimum FRA-Ti needed to improve the limiting oxygen index of asphalt is $8 \%$. In addition, the LOI of number 3 was the highest, which achieved $29.8 \%$ and belonged to the autoextinguished materials. It indicated that flame retardant is helpful in improving the flame retardant properties of asphalt.

3.3. Effect of Flame Retardant on the Pavement Performance of Asphalt Binder. Figure 6 shows the pavement performance indicators of asphalt binder with different dosage flame retardant. A general trend of softening point increase with increased dosage of FRA-Ti is observed, and the penetration, ductility, and elastic recovery become smaller. It can be concluded that the effect of flame retardant on pavement performance of asphalt is significant. The appropriate flame retardant and its dosage in the application process should be selected in order to guarantee the pavement performance of asphalt binder.

3.4. Determining the Formulations of Flame Retardant. As can be seen from the above analysis, the optimal dosage is $6 \%$ for nine FRA-Ti. The pavement performance and LOI results of asphalt binder with nine FRA-Ti are shown in Table 6 .

As mentioned above, the flame retardant not only must ensure the good flame retardant performance in asphalt but also should not significantly affect its pavement performance. Therefore, the several important factors should be considered when selecting the best formula for flame retardants. Firstly, it should be of consideration that the oil absorbing and activation index of nine FRA-Ti meet the basic requirements for flame retardant modification. In other words, oil absorption rate value should be small and activation index value is larger. Secondly, the pavement performance and LOI are important factors. In order to analyze the effect of every factor on the asphalts, the weights were calculated by the method of multiindex comprehensive score. It carries on comprehensive score calculation and comprehensive evaluation to merits based on confirming the index weight and index data normalization. A multi-index synthetic evolution model of weighted summation and weighted for components combination was selected [25] where Index is the test result of the index, $\mathrm{Min}_{\text {index }}$ is minimum of the index and $\mathrm{Max}_{\text {index }}$ is maximum of the index. Index membership is defined in

$$
\text { Membership }=\frac{\text { Index }- \text { Min }_{\text {index }}}{\operatorname{Max}_{\text {index }}-\text { Min }_{\text {index }}} .
$$

The index membership of pavement performance, LOI, oil absorbing, and activation index of nine asphalts with FRATi are shown in Table 7. It is evident that composite score of number 3 FRA-Ti was the highest. And it is a best recipe of flame retardant for asphalt binder. In addition, the sort of primary and secondary effects on the overall index factors is $\mathrm{Mg}(\mathrm{OH})_{2}$, melamine, APP, and titanate.

\section{Conclusion}

In this paper, a self-developed low dosage compound flame retardant has been prepared using orthogonal tests including four factors and three levels. The compound flame retardant was surface modified by titanate. The oil absorption and activation index were tested to evaluate the effect of titanate on the flame retardant. A series of asphalt binder tests were carried out to confirm the effect of flame retardant on the pavement performance. Oxygen index was tested to determine the effect of flame retardant on flammability of asphalt binder. From these test results, the following conclusions were drawn for the materials used in this study.

(1) The impact of titanate activation index and oil absorbing for flame retardants is significant. The optimal dosage of titanate is $6 \%$ for compound flame retardant considering the oil absorption and activation index.

(2) The compound flame retardant can significantly improve limiting oxygen index of asphalt binder. And the maximum increase is up to $8 \%$.

(3) The effect of flame retardant on pavement performance for asphalt binder is significant. One should select the appropriate flame retardant and its dosage in the application process in order to guarantee the pavement performance of asphalt binder.

(4) The addition of flame retardant, including magnesium hydroxide, ammonium polyphosphate, and melamine, can affect pavement performance and LOI differently. The best recipe of flame retardant for asphalt binder is $30 \%$ magnesium hydroxide, $46 \%$ ammonium polyphosphate, and $24 \%$ melamine.

(5) It is recommended to conduct another study to evaluate pavement performance and burning behavior of asphalt mixture using the flame retardant modified with titanate. Also, further study with many other flame retardant and surface modifications is needed to generalize these findings. 


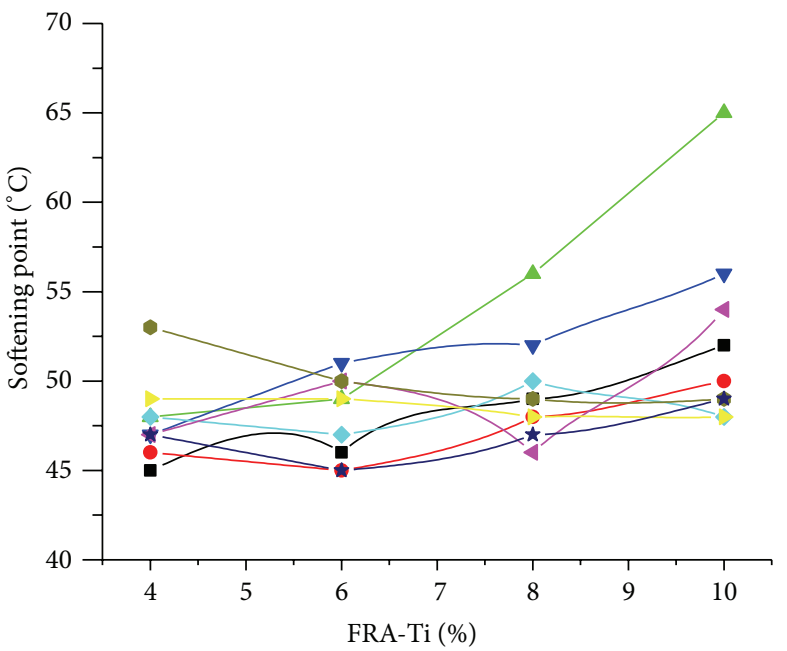

(a) Softening point of asphalt with FRA-Ti

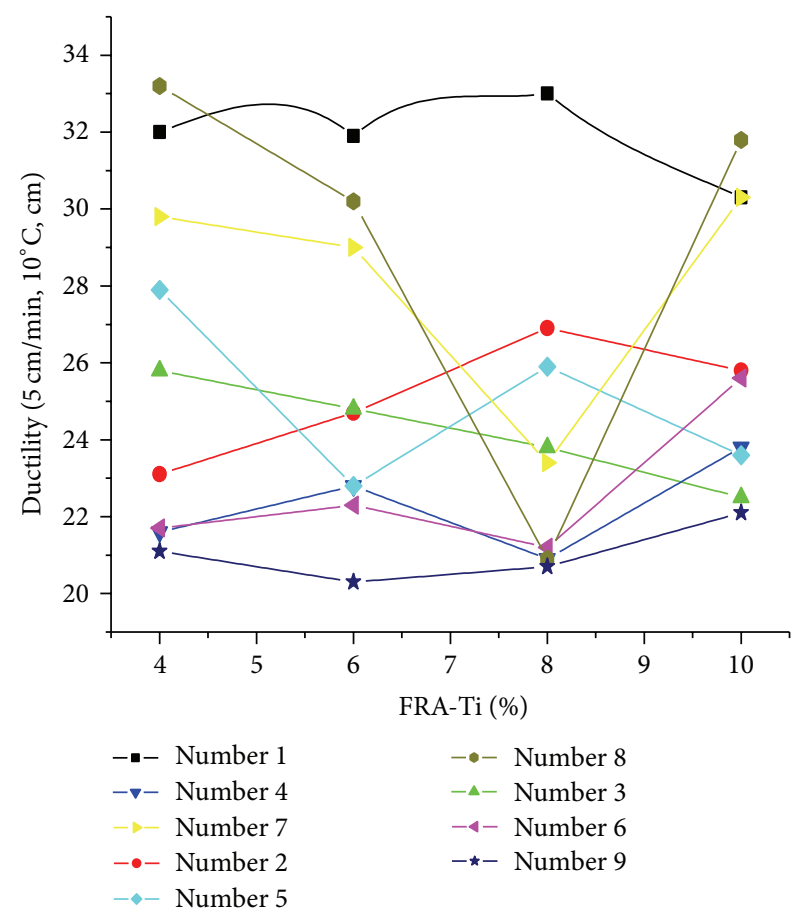

(c) Ductility of asphalt with FRA-Ti

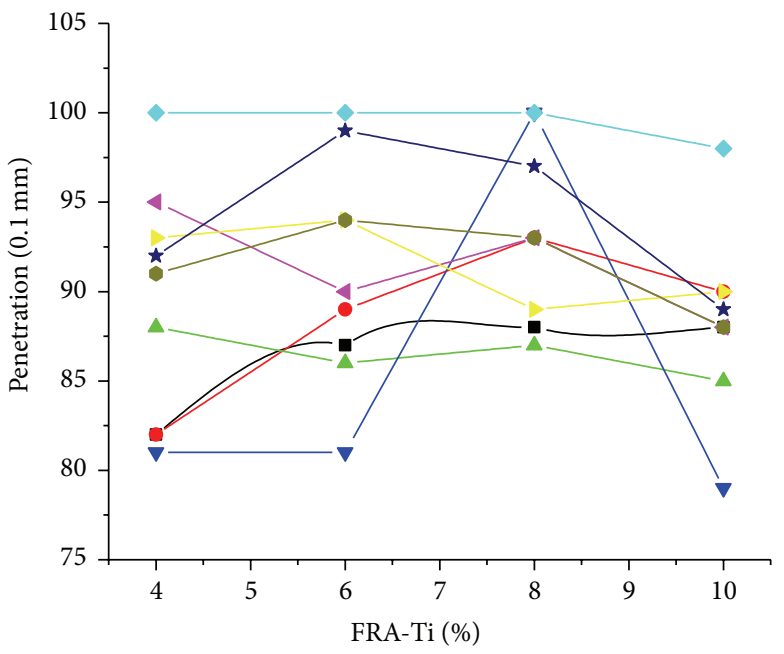

(b) Penetration of asphalt with FRA-Ti

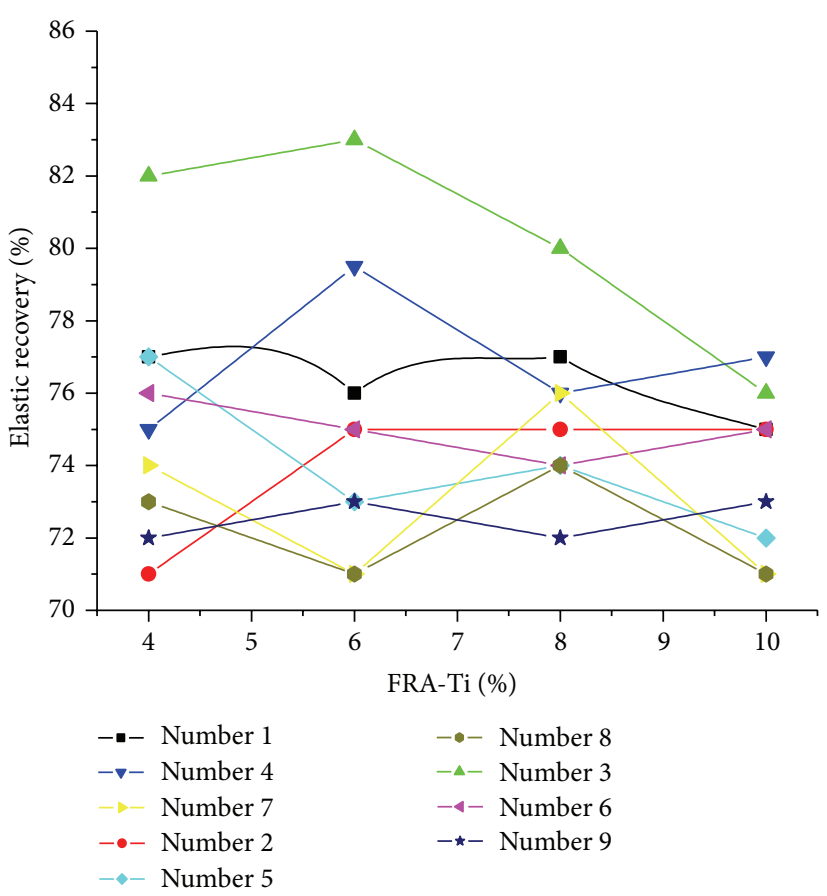

(d) Elastic recovery of asphalt with FRA-Ti

FIGURE 6: Pavement performance of asphalt with FRA-Ti.

TABLE 6: Test results of asphalt with FRA-Ti.

\begin{tabular}{lccccc}
\hline & Softening point $\left({ }^{\circ} \mathrm{C}\right)$ & Penetration $(0.1 \mathrm{~mm})$ & Ductility $\left(5 \mathrm{~cm} / \mathrm{min}, 10^{\circ} \mathrm{C}, \mathrm{cm}\right)$ & Elastic recovery $(\%)$ & LOI $(\%)$ \\
\hline Number 1 & 46 & 87 & 31.9 & 76 & 26.9 \\
Number 2 & 45 & 89 & 24.7 & 75 & 29.2 \\
Number 3 & 48 & 92 & 24.5 & 78 \\
Number 4 & 51 & 81 & 22.8 & 79.5 & 73 \\
Number 5 & 47 & 100 & 22.8 & 29.8 \\
Number 6 & 50 & 90 & 22.3 & 29.9 \\
Number 7 & 49 & 94 & 29 & 75 \\
Number 8 & 50 & 94 & 30.2 & 27.3 \\
Number 9 & 45 & 99 & 20.3 & 71 & 21.6 \\
\hline
\end{tabular}


TABLE 7: The index membership and composite score of FRA-Ti.

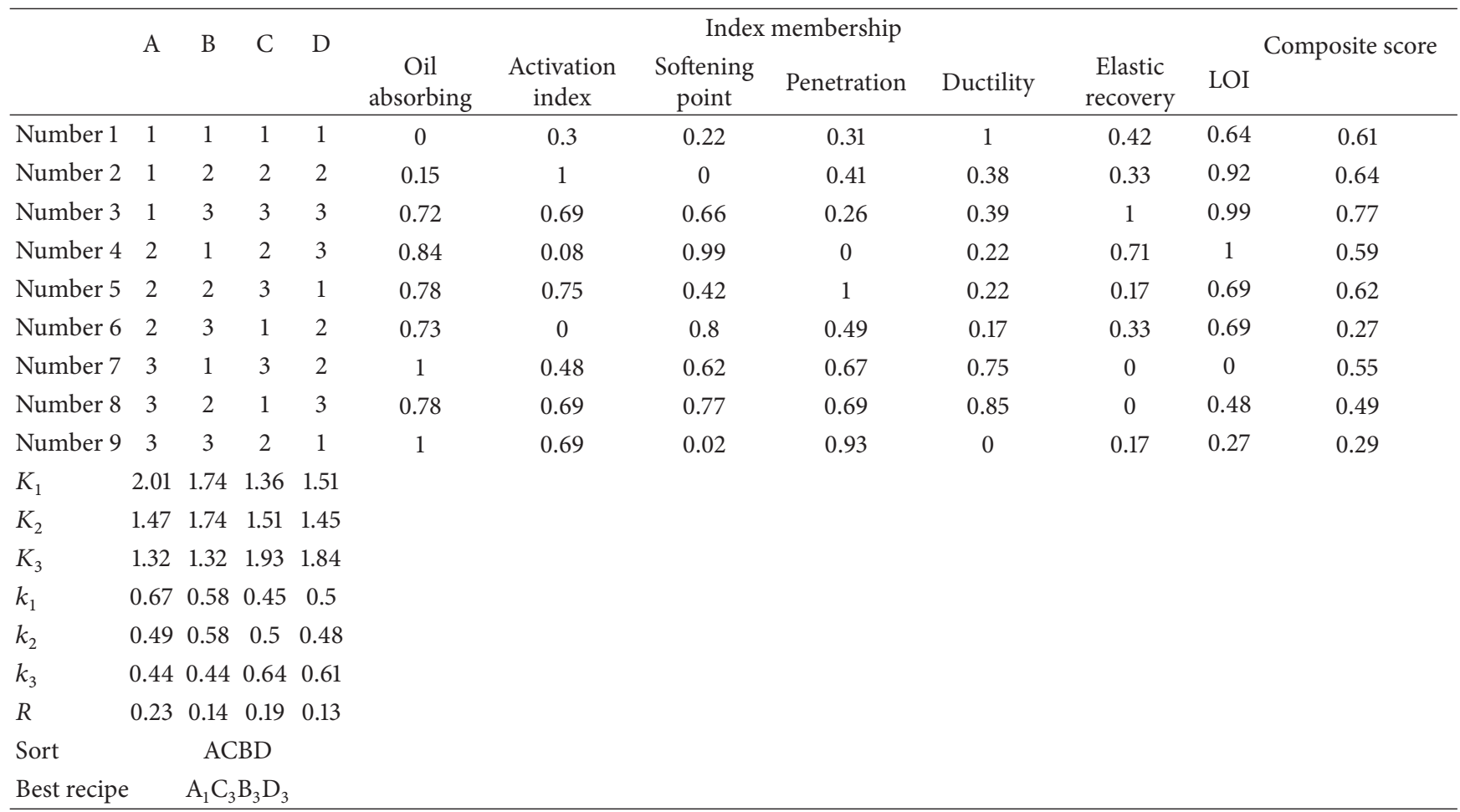

Note. $K_{1}, K_{2}$, and $K_{3}$ are sum of the index membership composite score of every sample at every factor and level, respectively. $k_{1}, k_{2}$, and $k_{3}$ are the average value of the index membership composite score of every sample at every factor and level, respectively. $R$ is the range of the index membership composite score of every sample at every factor and level, respectively.

\section{Conflict of Interests}

The authors declare that there is no conflict of interests regarding the publication of this paper.

\section{Acknowledgments}

The research work reported in this paper was sponsored by National Natural Science Foundation of China (51408287), Gansu DOT Research Project (2010-12), Program for Changjiang Scholars and Innovative Research Team in University (IRT1139), and Young Scholars Science Foundation of Lanzhou Jiaotong University (2011031). The authors would like to express thanks to all who have provided valuable help in this study.

\section{References}

[1] P. K. Das, N. Kringos, and B. Birgisson, "Microscale investigation of thin film surface aging of bitumen," Journal of Microscopy, vol. 254, no. 2, pp. 95-107, 2014.

[2] G. Wen, Y. Zhang, Y. Zhang, K. Sun, and Y. Fan, "Rheological characterization of storage-stable SBS-modified asphalts," Polymer Testing, vol. 21, no. 3, pp. 295-302, 2002.

[3] H. Yao, Z. You, L. Li et al., "Rheological properties and chemical analysis of nanoclay and carbon microfiber modified asphalt with Fourier transform infrared spectroscopy," Construction and Building Materials, vol. 38, pp. 327-337, 2013.
[4] S. Wu, L. Mo, P. Cong, J. Yu, and X. Luo, "Flammability and rheological behavior of mixed flame retardant modified asphalt binders," Fuel, vol. 87, no. 1, pp. 120-124, 2008.

[5] Y. Qun and Z. Y. Guo, "Mixture design of fire-retarded OGFC in road tunnel," Road Materials and Pavement Design, vol. 6, no. 2, pp. 255-268, 2005.

[6] A. Leitner, "The fire catastrophe in the Tauern Tunnel: experience and conclusions for the Austrian guidelines," Tunnelling and Underground Space Technology, vol. 16, no. 3, pp. 217-223, 2001.

[7] A. Lönnermark and H. Ingason, "Gas temperatures in heavy goods vehicle fires in tunnels," Fire Safety Journal, vol. 40, no. 6, pp. 506-527, 2005.

[8] S. Wu, P. Cong, J. Yu, X. Luo, and L. Mo, "Experimental investigation of related properties of asphalt binders containing various flame retardants," Fuel, vol. 85, no. 9, pp. 1298-1304, 2006.

[9] "Fire retardant asphalt composition. Add polymer," Patent US 5026747, 1991.

[10] H. Demir, E. Arkiş, D. Balköse, and S. Ülkü, "Synergistic effect of natural zeolites on flame retardant additives," Polymer Degradation and Stability, vol. 89, no. 3, pp. 478-483, 2005.

[11] A. Toldy, N. Tóth, P. Anna, and G. Marosi, "Synthesis of phosphorus-based flame retardant systems and their use in an epoxy resin," Polymer Degradation and Stability, vol. 91, no. 3, pp. 585-592, 2006.

[12] F. Laoutid, L. Ferry, J. M. Lopez-Cuesta, and A. Crespy, "Flameretardant action of red phosphorus/magnesium oxide and red phosphorus/iron oxide compositions in recycled PET," Fire and Materials, vol. 30, no. 5, pp. 343-358, 2006. 
[13] M. Sain, S. H. Park, F. Suhara, and S. Law, "Flame retardant and mechanical properties of natural fibre-PP composites containing magnesium hydroxide," Polymer Degradation and Stability, vol. 83, no. 2, pp. 363-367, 2004.

[14] J. M. Laza, E. Bilbao, M. T. Garay, J. L. Vilas, M. Rodríguez, and L. M. León, "Thermal properties and fire behaviour of materials produced from curing mixed epoxy and phenolic resins," Fire and Materials, vol. 32, no. 5, pp. 281-292, 2008.

[15] X. Chen, J. Yu, and S. Guo, "Structure and properties of polypropylene composites filled with magnesium hydroxide," Journal of Applied Polymer Science, vol. 102, no. 5, pp. 4943-4951, 2006.

[16] S. A. A. Ramazani, A. Rahimi, M. Frounchi, and S. Radman, "Investigation of flame retardancy and physical-mechanical properties of zinc borate and aluminum hydroxide propylene composites," Materials and Design, vol. 29, no. 5, pp. 1051-1056, 2008.

[17] N. Huang and J. Wang, "A TGA-FTIR study on the effect of $\mathrm{CaCO}_{3}$ on the thermal degradation of EBA copolymer," Journal of Analytical and Applied Pyrolysis, vol. 84, no. 2, pp. 124-130, 2009.

[18] T. Xu and X. Huang, "Pyrolysis properties and kinetic model of an asphalt binder containing a flame retardant," Journal of Applied Polymer Science, vol. 119, no. 5, pp. 2661-2665, 2011.

[19] H.-Q. Chen and P.-W. Hao, "Development of the modified fireretardant asphalt and performance evaluation on its mixture," Journal of Wuhan University of Technology, vol. 30, no. 12, pp. 58-62, 2008.

[20] S.-Y. Lu and I. Hamerton, "Recent developments in the chemistry of halogen-free flame retardant polymers," Progress in Polymer Science, vol. 27, no. 8, pp. 1661-1712, 2002.

[21] G. Chunsuo and C. Chengzhi, "Study on surface modification of inorganic fillers with titanate coupling agent," Technology \& Development of Chemical Industry, vol. 36, no. 9, pp. 4-7, 2007.

[22] M. Zhiling, F. congran, and M. Xin, "Coupling function of titanate coupling agent in PP/IFR composites," China Plastics, vol. 25, no. 10, pp. 77-80, 2011.

[23] H.-Q. Chen and P.-W. Hao, "Research on the surface modification of fire-retardant asphalt with titanate coupling agent," Journal of Wuhan University of Technology, vol. 31, no. 17, pp. 66-69, 2009.

[24] C. Hui-qiang and C. Shi-zhou, "Research on asphalt flame re-tardant modification technology," Journal of Highway and Transportation Research and Development, no. 2, pp. 19-20, 2003.

[25] B. Li, S. Han, O.-M. Xu, and X.-Q. Teng, "Evaluation of asphalt pavement performance based on principal component analysis," Journal of Chang'an University, vol. 29, no. 3, pp. 15-18, 2009. 

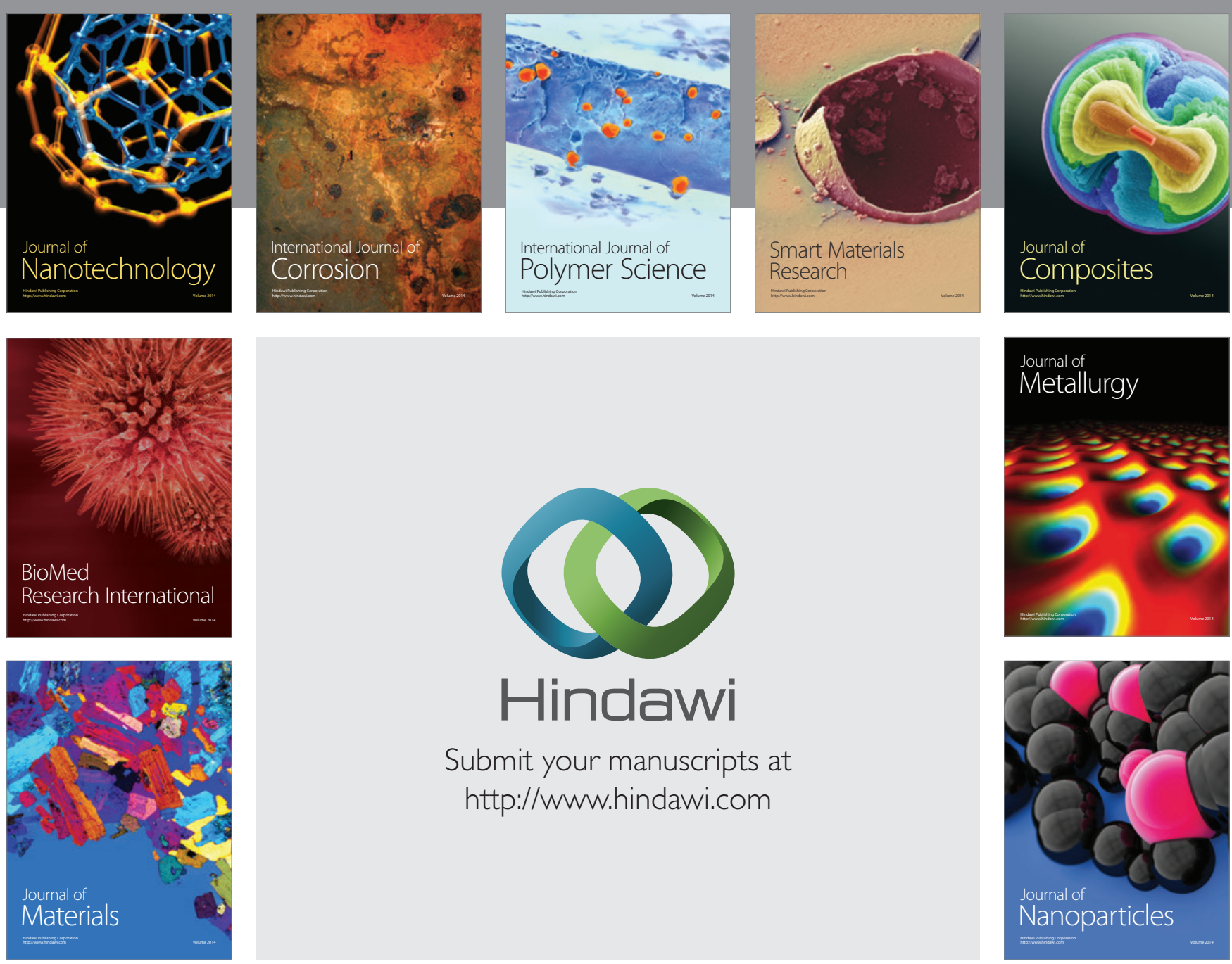

Submit your manuscripts at http://www.hindawi.com
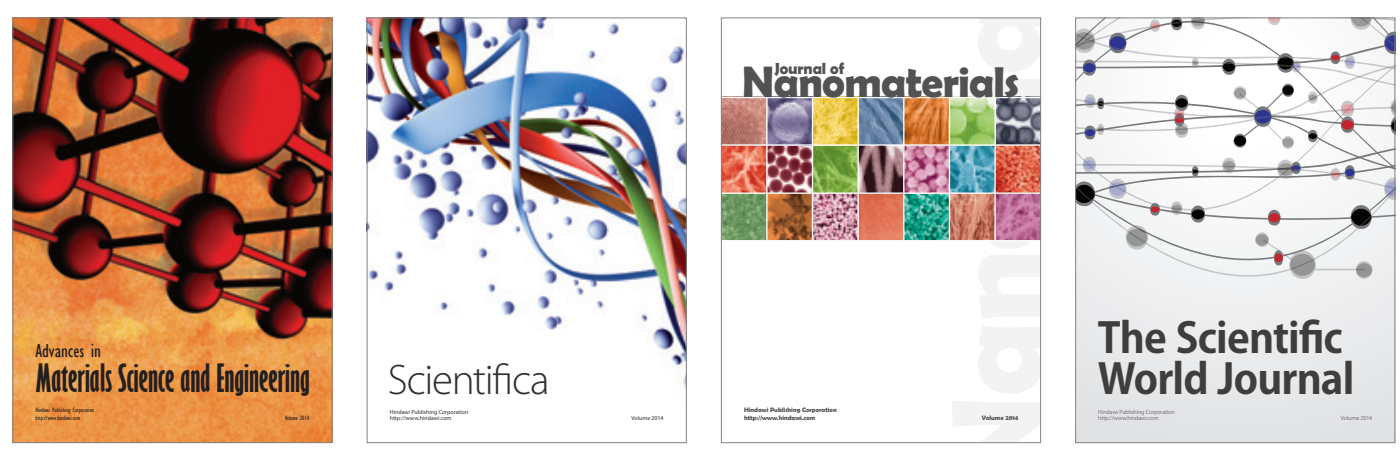

\section{The Scientific World Journal}
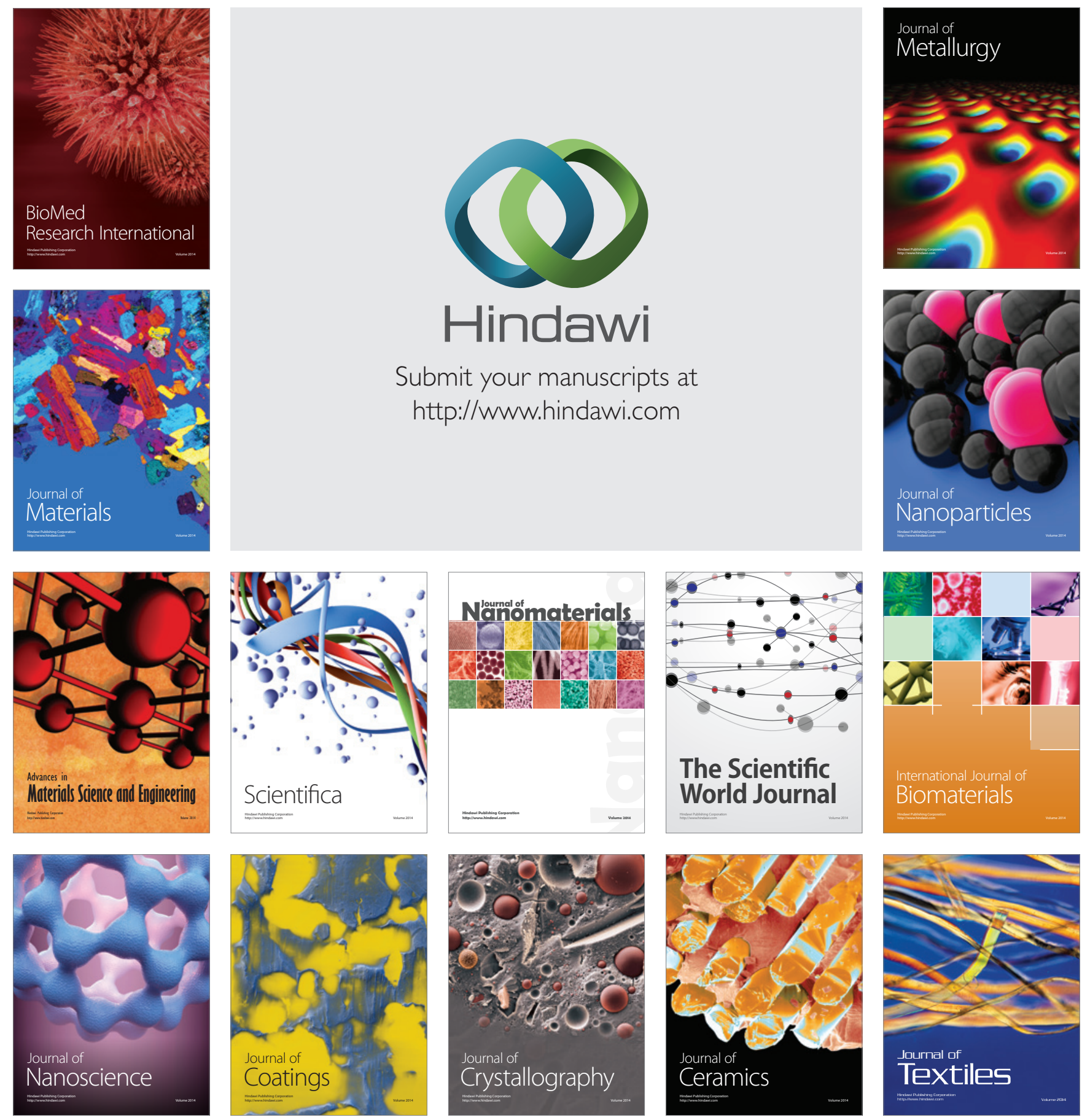